\title{
Perancangan Model Human Capital Readiness Tenaga Kependidikan yang Terlibat dalam Core Process Departemen di Institut Teknologi Sepuluh Nopember (Studi Kasus : Departemen Teknik Industri)
}

\author{
Rada Febbyandani Sugianto dan Naning Aranti Wessiani \\ Departemen Teknik Industri, Fakultas Teknologi Industri, Institut Teknologi Sepuluh Nopember (ITS) \\ e-mail: radafebbyandani@ gmail.com
}

\begin{abstract}
Abstrak-Perubahan status ITS dari PTN-BLU menjadi PTNBH menyebabkan ITS harus mengubah tatanan birokrasi agar sesuai dengan tatanan PTN-BH, salah satunya terkait dengan sumber daya manusia. Selain itu, tenaga kependidikan di ITS juga dituntut untuk dapat mensukseskan target organisasi yang semakin tinggi. Namun saat ini, di ITS belum memiliki pengukuran kesiapan tenaga kependidikan yang terstruktur yang mana menyebabkan ITS kesulitan dalam mengelola tenaga kependidikan saat ini. Oleh sebab itu, dilakukan perancangan model pengukuran Human Capital Readiness untuk mengetahui level kesiapan tenaga kependidikan. Hasil dari pengukuran dapat digunakan sebagai analisis untuk perancangan program pengembangan human capital sehingga kompetensi tenaga kependidikan dapat sesuai dengam kebutuhan. Penelitian ini dilakukan dengan identifikasi proses bisnis identifikasi unit kerja dan pemetaan jabatan yang terlibat dalam core process. Selanjutnya dilakukan identifikasi kompetensi serta tools dan resource yang digunakan. Kemudian dilanjutkan validasi dan penentuan target oleh expert kemudian pembuatan scorecard pengukuran Human Capital Readiness. Hasil dari penelitian ini yaitu jabatan yang terlibat langsung dalam core process di Departemen adalah Pengadministrasi akademik, Pengadministrasi mahasiswa dan alumni, Petugas perpustkaan dan Teknisi Sarana Prasarana. Dimensi Human Capital Readiness yaitu kompetemsi inti, pendukung dan teknis, tools serta resource. Hasil identifikasi kompetensi yaitu 7 kompetensi inti, 13 Kompetensi Pendukung dan 16 Kompetensi Teknis untuk Jabatan Pengadministrasian Akademik, 11 Kompetensi Pendukung dan 8 Kompetensi Teknis untuk Jabatan Pengadministrasi Kemahasiswaan dan alumni, serta 12 Kompetensi pendukung dan 8 Kompetensi Teknis untuk Petugas Perpustakaan dan Teknisi Sarana Prasarana.
\end{abstract}

Kata Kunci-Jabatan, Kompetensi, Core Process, Human Capital Readiness.

\section{PENDAHULUAN}

$\mathrm{P}$ ENDIDIKAN merupakan salah satu indikator pembangunan ekonomi suatu negara. Apabila tingkat pendidikan masyarakat tinggi maka pembangunan ekonomi negara tersebut bagus. Pendidikan saat ini telah mengalami banyak perubahan kebijakan secara dinamis, yang mana bertujuan untuk menciptakan generasi cerdas sehingga siap untuk bersaing secara global di segala bidang. Berdasarkan Peraturan Pemerintah Nomor 83 Tahun 2014, Institut Teknologi Sepuluh Nopember (ITS) mengalami perubahan bentuk dan mekanisme pengelolaan pendanaan perguruan tinggi dari PTNBLU menjadi perguruan tinggi badan hukum milik negara ( PT BHMN) atau PTN-BH. Perubahan status tersebut, menyebabkan ITS harus mengubah tatanan birokrasi agar sesuai dengan PTN-BH. Dalam pengimplementasian PTN-BH terdapat delapan area kunci perubahan birokrasi.

Salah satu perubahan yang perlu diperhatikan adalah aspek sumber daya manusia. Sumber daya manusia dapat dianggap sebagai intangible asset atau aset yang tidak berwujud yang dapat menjadi keungulan kompetitif suatu organisasi. Hal tersebut selaras dengan konsep human capital yang menjelaskan bahwa manusia dalam organisasi dan bisnis merupakan aset yang penting dan memiliki esensi, yang menyumbang terhadap pertumbuhan dan pengembangan sama seperti aset fisik seperti mesin dan modal kerja. Sikap, skill dan kemampuan manusia memiliki kontribusi terhadap kinerja dan produktivitas organisasi. Pengeluaran untuk pelatihan, pengembangan, kesehatan dan dukungan merupakan investasi bukan hanya beban.

Perubahan status dari PTN-BLU menjadi PTN-BH memerlukan sumber daya manusia yang mampu merespon dengan cepat adanya perubahan serta sumber daya manusia yang mampu dengan cakap menyesuaikan diri terhadap perubahan. Selain itu, tenaga kependidikan di ITS juga dituntut untuk dapat mensukseskan target organisasi yang semakin tinggi dibandingkan dengan sebelumnya. Namun, saat ini di ITS belum memiliki sebuah pengukuran kesiapan tenaga kependidikan yang terstruktur. Apabila level kesiapan tenaga kerja tidak diketahui, maka ITS akan kesulitan dalam mengelola tenaga kependidikan saat ini. Dengan adanya pengukuran level kesiapan tenaga kependidikan saat ini, dapat diketahui pengembangan tenaga kependidikan yang dapat dilakukan sehingga tenaga kependidikan yang ada di ITS dapat sesuai dengen kebutuhan dalam mencapai target organisasi. Hal tersebut sesuai dengan pernyataan Rektor ITS bahwa dengan 
adanya otonomi PTN-BH, Institut Teknologi Sepuluh Nopember diharapkan memiliki tata kelola yang baik untuk lebih berkembang dan inovatif dari segi instutusi dan sumber daya. Oleh sebab itu, Institut Teknologi Sepuluh Nopember perlu melakukan pengukuran kesiapan human capital untuk mengetahui seberapa siap tenaga - tenaga kependidikan yang ada di Institut Teknologi Sepuluh Nopember saat ini.

Penelitian ini bertujuan untuk melakukan perancangan model human capital readiness tenaga kependidikan yang terlibat langsung dalam proses inti ITS. Perancangan human capital readiness dapat membantu mengetahui jabatan - jabatan yang terlibat dalam proses bisnis inti (Core Process) ITS yang sesuai dengan Tridharma Perguruan Tinggi yaitu Pendidikan, Penelitian dan Pengabdian Masyarakat serta membantu organisasi mengetahui seberapa siap tenaga kependidikan saat ini.

\section{METODOLOGI PENELITIAN}

\section{A. Tahap Pendahuluan}

Pada tahap pendahuluan, dilakukan identifikasi permasalahan terkait dengan kesiapan human capital dengan adanya perubahan bentuk ITS menjadi Perguruan Tinggi Negeri Badan Hukum (PTN-BH).Setelah itu penulis melakukan penetapan tujuan dan manfaat dan dilakukan studi literatur yang terdiri dari Manajemen Sumber Daya Manusia (MSDM), Manajemen Kinerja, Learning and Growth pada Balance Scorecard, Human Capital Readiness, Kompetensi, Kamus kompetensi dan Taxonomy Bloom. Kemudian dilakukan pengamatan langsung terhadap Departemen Teknik Industri ITS.

\section{B. Tahap Pengumpulan dan Pengolahan Data}

Pengumpulan data berupa visi, misi dan strategi ITS serta profil Departemen Teknik Industri. Kemudian, dilakukan identifikasi jabatan tenaga kependidikan dengan melakukan wawancara terhadap Kepala Departemen Teknik Industri ITS serta, pengumpulan job description pada seluruh tenaga kependidikan dalam Departemen Teknik Industri kepada Sub direktorat Sumber Daya Manusia ITS. Pengolahan data yang dilakukan adalah pemetaan proses bisnis ITS dengan model CIMOSA Selanjutnya dilakukan identifikasi unit kerja yang terlibat secara langsung pada core process ITS serta dilakukan identifikasi tenaga kependidikan yang terlibat langsung pada departemen. Langkah selanjutnya yaitu identifikasi dimensi human capital readiness Setelah itu, dilakukan penyusunan daftar kompetensi. Setelah diketahui kompetensinya maka dilakukan penentuan tools dan resource. Setelah itu dilakukan penyusunan indikator penilaian kompetensi. Penyusunan level indikator sebanyak enam level dibuat dengan berdasarkan Taxonomy Bloom dan Kamus Kompetensi. Setelah itu dilakukan validasi terhadap indikator yang telah ditentukan dengan expert judgement dan pembuatan mekanisme serta model pengukuran Human Capital Readiness.

\section{Tahap Analisis dan Interpretasi Data}

Pada tahap ini dilakukan analisis terhadap hasil pengolahan data yang telah diperoleh sebelumnya. Analis is yang dilakukan antara lain adalah analisis jabatan yang terlibat dalam core process ITS berdasarkan Tridharma Perguruan Tinggi, analisis daftar kompetensi, analis is tools dan resource yang digunakan, analisis indikator penilaian dan analisis scorecard model pengukuran Human Capital Readiness.

\section{Tahap Kesimpulan dan Saran}

Tahapan terakhir adalah penarikan kesimpulan dan saran. Kesimpulan yang dinyatakan harus menjawab tujuan penelitian yang telah dipaparkan sebelumnya. Kesimpulan tersebut berdasarkan hasil analisis dan interpretasi data dari hasil pengolahan data yang telah dilakukan. Setelah itu dilakukan pemberian saran terkait penelitian lebih lanjut.

\section{HASIL DAN PEMBAHASAN}

\section{A. Identifikasi Jabatan}

Identifikasi jabatan tenaga kependidikan yang terlibat dalam proses bisnis inti ITS dilakukan dengan pemetaan proses bisnis menggunakan CIMOSA (Computer Integrated Manufacturing Open System Architecture). Pemetaan proses bisnis dilakukan dalam dua level. Pada level pertama dilakukan pemetaan secara umum. Pada level dua merupakan penjabaran dari setiap proses di level satu.. Berikut ini merupakan hasil identifikasi proses bisnis serta tenaga kependidikan departemen yang terlibat dalam core process.

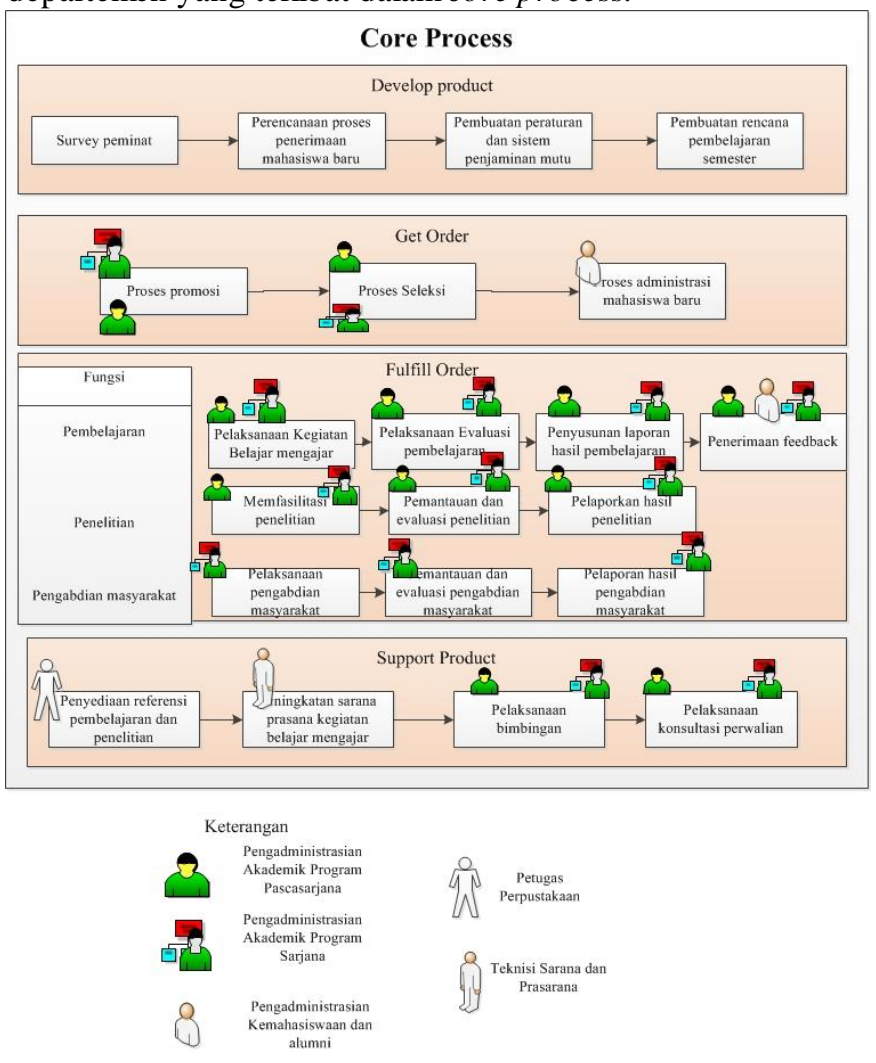

Gambar 1. Hasil Pemetaan Tenaga Kependidikan Departemen pada Core Process

\section{B. Identifikasi Dimensi Human Capital Readiness}

Berdasarkan studi literatur [1], [2] dan [3]. Dimensi yang akan diukur dalam rancangan model ini adalah kompetensi 
yang terdiri dari kompetensi inti, kompetensi teknis dan kompetensi teknis serta tools dan resource yang dilagunakan. Penentuan dimensi kompetensi tidak hanya didasarkan pada studi literatur namun juga mempertimbangkan kondisi pengukuran kinerja tenaga kependidikan di ITS saat ini yang belum memiliki pengukuran mengenai kompetensi serta tools dan resource yang digunakan. Dengan adanya pengukuran kompetensi, tools serta resource diharapkan dapat memberikan kemudahan dalam melakukan pengembangan kemampuan tenaga kependidikan.

\section{Identifikasi Kompetensi}

Identifikasi kompetensi terdiri dari tiga tahap yaitu identifikasi kompetensi inti, kompetensi pendukung dan kompetensi teknis.

Proses identifikasi kompetensi inti berdasarkan visi, misi, tujuan strategis, strategi dan tata nilai ITS. Kata kunci merupakan poin utama yang merupakan kata inti dari kalimat visi, misi, strategi dan tata nilai ITS. Kemudian kata kunci dicocokkan dengan kamus kompetensi Spencer - Spencer, University of Guelph dan Harvard. Kompetensi inti merupakan kompetensi yang harus dimiliki oleh setiap tenaga kependidikan di ITS. Berikut ini merupakan contoh pengidentifikasian kompetensi inti yang dilakukan :

Visi ITS : "Menjadi perguruan tinggi dengan reputasi internasional dalam ilmu pengetahuan, teknologi, dan seni, terutama yang menunjang industri dan kelautan yang berwawan lingkungan"

Berdasarkan kalimat visi ITS tersebut terdapat tiga kata kunci yang dapat diidentifikasi salah satunya yaitu menunjang industri kelautan. Berdasarkan kamus kompetensi Spencer \& Spencer, University of Guelph dan Harvard kata kunci menunjang industri kelautan tersebut membutuhkan kompetensi impact and influence yang mana kompetensi ini dibutuhkan agar seseorang mengetahui bahwa segala tindakan yang dilakukan dapat mempengaruhi pencapaian dan memberikan dampak bagi industri. Terdapat 7 kompetensi inti yang berhasil diidentifikasi. Berikut ini merupakan tabel hasil identifikasi kompetensi inti.

Tabel 1.

Hasil Identifikasi Kompetensi Inti

\begin{tabular}{ccccccc}
\hline \hline No & $\begin{array}{c}\text { Kompetensi } \\
\text { Inti }\end{array}$ & Visi & Misi & $\begin{array}{c}\text { Tujuan } \\
\text { Strategis }\end{array}$ & Strategi & $\begin{array}{c}\text { Tata } \\
\text { Nilai }\end{array}$ \\
\hline 1 & $\begin{array}{c}\text { Achievement } \\
\text { Orientation } \\
2\end{array}$ & $\sqrt{ }$ & $\sqrt{ }$ & $\sqrt{ }$ & $\sqrt{ }$ & $\sqrt{ }$ \\
& $\begin{array}{c}\text { Impact and } \\
\text { Influence } \\
\text { Organizational } \\
\text { Commitment } \\
\text { Relationship } \\
\text { Building }\end{array}$ & $\sqrt{ }$ & $\sqrt{ }$ & $\sqrt{ }$ & $\sqrt{ }$ & \\
5 & $\begin{array}{c}\text { Continuous } \\
\text { Learning } \\
\text { Creative }\end{array}$ & $\sqrt{ }$ & & & $\sqrt{ }$ \\
6 & Thingking \\
Team & Leadership & $\sqrt{ }$ & & $\sqrt{ }$ & $\sqrt{ }$ \\
7 & & & & $\sqrt{ }$ & \\
\hline \hline
\end{tabular}

Identifikasi kompetensi pendukung dilakukan dengan mengidentifikasi rincian tugas pada masing - masing jabatan yang terdapat pada job description. Kompetensi pendukung merupakan kompetensi yang berkaitan dengan deskripsi jabatan. Kompetensi ini harus dimiliki oleh pemilik jabatan agar dapat melaksanakan pekerjaan dengan baik. Berikut ini merupakan salah satu langkah dalam identifikasi kompetensi pendukung.

Rincian tugas : " membantu melakukan penyusunan jadwal perkuliahan, ruang perkuliahan, dan dosen pengampu mata kuliah"

Berdasarkan rincian tugas tersebut dengan berpedoman pada kamus kompetensi Spencer \& Spencer, University of Guelph dan Harvard dibutuhkan kompetensi Planning and Organizing yang mana tenaga kependidikan harus memiliki kompetensi untuk mempu melakukan perencanaan dan pengorganisasian terhadap suatu hal. Berikut ini merupakan salah satu hasil identifikasi kompetensi pendukung pada jabatan Pengadministrasi program pascasarjana dan Program Sarjana

Tabel 2 .

Hasil Identifikasi Kompetensi Pendukung Pengadministrasi Akademik Program Sarjana dan Pascasarjana

\begin{tabular}{|c|c|c|c|}
\hline $\begin{array}{l}\mathrm{N} \\
\mathrm{O}\end{array}$ & $\begin{array}{c}\text { Kompetensi } \\
\text { Pendukung }\end{array}$ & $\begin{array}{c}\text { Kod } \\
\mathrm{e}\end{array}$ & Referensi \\
\hline 1 & $\begin{array}{l}\text { Planning and } \\
\text { Organizing }\end{array}$ & $\mathrm{PO}$ & $\begin{array}{l}\text { Kamus Kompetensi University } \\
\text { of Guelph }\end{array}$ \\
\hline 2 & Information Seeking & $\begin{array}{l}\text { INF } \\
\text { O }\end{array}$ & $\begin{array}{l}\text { Kamus Kompetensi Spencer \& } \\
\text { Spencer }\end{array}$ \\
\hline 3 & Communication & $\mathrm{CM}$ & $\begin{array}{l}\text { Kamus Kompetensi University } \\
\text { of Guelph }\end{array}$ \\
\hline 4 & Concern for Order & $\mathrm{CO}$ & $\begin{array}{l}\text { Kamus Kompetensi Spencer \& } \\
\text { Spencer }\end{array}$ \\
\hline 5 & Initiative & INT & $\begin{array}{l}\text { Kamus Kompetensi University } \\
\text { of Guelph }\end{array}$ \\
\hline 6 & Managing Work & MW & Kamus Kompetensi Harvard \\
\hline 7 & $\begin{array}{l}\text { Technical/Profession } \\
\text { al Skill }\end{array}$ & EXP & Kamus Kompetensi Harvard \\
\hline 8 & Directiveness & DIR & $\begin{array}{l}\text { Kamus Kompetensi Spencer \& } \\
\text { Spencer }\end{array}$ \\
\hline 9 & Follow Up & FO & Kamus Kompetensi Harvard \\
\hline 10 & $\begin{array}{l}\text { Teamwork and } \\
\text { Cooperation }\end{array}$ & $\mathrm{TW}$ & $\begin{array}{l}\text { Kamus Kompetensi Spencer \& } \\
\text { Spencer }\end{array}$ \\
\hline 11 & $\begin{array}{l}\text { Customer Service } \\
\text { Orientation }\end{array}$ & CSO & $\begin{array}{l}\text { Kamus Kompetensi Spencer \& } \\
\text { Spencer }\end{array}$ \\
\hline 12 & Flexibility & FLX & $\begin{array}{l}\text { Kamus Kompetensi Spencer \& } \\
\text { Spencer }\end{array}$ \\
\hline 13 & $\begin{array}{l}\text { Meeting } \\
\text { Partisipation }\end{array}$ & MP & Kamus Kompetensi Harvard \\
\hline
\end{tabular}

Dalam melakukan identifikasi kompetensi pendukung sangat dipengaruhi oleh rincian tugas yang terdapat pada job description. Apabila terdapat perubahan rincian tugas maka menyebabkan kompetensi yang diperlukan berubah.

Pada proses identifikasi kompetensi teknis dilakukan dengan mengidentifikasi rincian tugas dalam deskripsi jabatan untuk diketahui pengetahuan dan kemampuan teknis yang diperlukan pada setiap tenaga kependidikan. Kompetensi teknis lebih spesifik berdasarkan pekerjaan di setiap pekerja [4]. Berikut ini 
merupakan hasil identifikasi kompetensi teknis tenaga kependidikan departemen.

Tabel 3.

Hasil Identifikasi Kompetensi Teknis Pengadministrasi Akademik Program Pascasarjana

\section{Kompetensi Teknis}

Mampu menyusun jadwal perkuliahan dan perwalian

Mampu melakukan input data pada SIM Akademik

Mampu menyiapkan form kendali perkuliahan

Mampu menyusun jadwal seminar at au sidang

Mampu menyusun laporan kemajuan Thesis / Disertasi mahasiswa

Mampu melakukan rekap nilai dan revisi seminar atau sidang

Thesis/Disertasi

Mampu menyusun jadwal evaluasi perkuliahan

Mampu menyiapkan paket soal Evaluasi Perkuliahan

Mampu melakukan monitoring perkuliahan

Mampu membuat berita acara pelanggaran dalam evaluasi

pembelajaran tiap mata kuliah

Mampu membuat surat ijin penelitian / pengamatan/kunjungan ke pihak internal dan eksternal

Mengetahui sistem seleksi masuk perguruan tinggi

Menyiapkan administrasi dan pelaksanaan yudisium di tingkat

Departemen

Mampu menyusun jadwal ujian wawancara calon mahasiswa

Mampu mengolah data akademik

Mampu memberikan informasi akademik kepada dosen maupun mahasiswa

Berdasarkan identifikasi yang telah dilakukan diperoleh 16 kompetensi teknis untuk jabatan Pengadministrasi akademik program Pascasarjana, sama halnya dengan jabatan Pengadministrasi akademik program Sarjana yang memiliki 16 kompetensi teknis. Sedangkan jabatan pengadministrasi kemahasiswaan dan alumni, petugas perpustakaan dan teknisi sarana prasarana memiliki 8 kompetensi teknis.

\section{Identifikasi Tools dan Resource}

Proses identifikasi tools dan resource yang digunakan oleh tenaga kependidikan dilakukan berdasarkan kompetensi yang telah ditentukan. Kompetensi yang digunakan dalam penentuan tools dan resource ini yaitu kompetensi teknis dikarenakan kompetensi teknis yang berkaitan erat dengan teknis pekerjaan tenaga kependidikan. Penentuan tools dan resource juga berdasarkan pada proses kerja untuk menjalankan suatu tugas tersebut yang diperoleh melalui wawancara dengan tenaga kependidikan tersebut. Berikut ini merupakan hasil identifikasi tools dan resource untuk tenaga kependidikan Pengadministrasi Program Pascasarjana.

Tabel 4.

Hasil Identifikasi Tools dan resource Pengadministrasi Akademik Program Pascasarjana

\begin{tabular}{ccc}
\hline \hline Kompetensi Teknis & Tools & Resource \\
\hline $\begin{array}{c}\text { Mampu menyusun jadwal } \\
\text { perkuliahan dan } \\
\text { perwalian }\end{array}$ & Ms.Excel & $\begin{array}{c}\text { Data mata kuliah, Data } \\
\text { ruang kelas, data } \\
\text { availabilitas dosen }\end{array}$ \\
$\begin{array}{c}\text { Mampu melakukan input } \\
\text { data pada SIM Akademik } \\
\text { Mampu menyiapkan }\end{array}$ & $\begin{array}{c}\text { SIM } \\
\text { Akademik }\end{array}$ & $\begin{array}{c}\text { Ms.Word, } \\
\text { mahasiswa, dosen, }\end{array}$ \\
& & Daftar mahasiswa,
\end{tabular}

\begin{tabular}{|c|c|c|}
\hline Kompetensi Teknis & Tools & Resource \\
\hline form kendali perkuliahan & Ms.Excel & Rencana Pembelajaran \\
\hline $\begin{array}{c}\text { Mampu menyusun jadwal } \\
\text { seminar atau sidang }\end{array}$ & Ms.Excel & $\begin{array}{c}\text { Data mahasiswa, lembar } \\
\text { pengajuan seminar atau } \\
\text { sidang }\end{array}$ \\
\hline $\begin{array}{l}\text { Mampu menyusun } \\
\text { laporan kemajuan Thesis } \\
\text { / Disertasi mahasiswa }\end{array}$ & Ms.Word & Data kemajuan thesis \\
\hline $\begin{array}{c}\text { Mampu melakukan rekap } \\
\text { nilai dan revisi seminar } \\
\text { atau sidang } \\
\text { Thesis/Disertasi }\end{array}$ & Ms. Excel & $\begin{array}{l}\text { Lembar revisi seminar } \\
\text { atau sidang } \\
\text { Thesis/Disertasi, Lembar } \\
\text { penilaian seminar atau } \\
\text { sidang Thesis/Disertasi, }\end{array}$ \\
\hline $\begin{array}{l}\text { Mampu menyusun jadwal } \\
\text { evaluasi perkuliahan }\end{array}$ & Ms. Excel & Jadwal perkuliahan \\
\hline $\begin{array}{c}\text { Mampu menyiapkan } \\
\text { paket soal Evaluasi } \\
\text { Perkuliahan }\end{array}$ & Ms.Word & Paket soal \\
\hline $\begin{array}{c}\text { Mampu melakukan } \\
\text { monitoring perkuliahan } \\
\text { Mampu membuat berita }\end{array}$ & $\begin{array}{c}\text { SIM } \\
\text { Akademik }\end{array}$ & $\begin{array}{l}\text { Absensi perkuliahan, } \\
\text { Rencana Pembelajaran }\end{array}$ \\
\hline $\begin{array}{l}\text { acara pelanggaran dalam } \\
\text { evaluasi pembelajaran } \\
\text { tiap mata kuliah }\end{array}$ & Ms.Word & $\begin{array}{l}\text { Identitas Mahasiswa, } \\
\text { Jenis pelanggaran }\end{array}$ \\
\hline $\begin{array}{c}\text { Mampu membuat surat } \\
\text { ijin penelitian / } \\
\text { pengamatan/kunjungan } \\
\text { ke pihak internal dan } \\
\text { eksternal }\end{array}$ & Ms.Word & $\begin{array}{l}\text { Identitas mahasiswa, } \\
\text { Kepentingan mahasiswa }\end{array}$ \\
\hline $\begin{array}{c}\text { Mengetahui sistem } \\
\text { seleksi masuk perguruan } \\
\text { tinggi }\end{array}$ & $\begin{array}{c}\text { Website } \\
\text { Pascasarjana }\end{array}$ & $\begin{array}{c}\text { Kebijakan penerimaan } \\
\text { mahasiswa baru }\end{array}$ \\
\hline $\begin{array}{c}\text { Menyiapkan administrasi } \\
\text { dan pelaksanaan yudisium } \\
\text { di tingkat Departemen }\end{array}$ & $\begin{array}{l}\text { Ms.Word, } \\
\text { Ms.Excel }\end{array}$ & Berkas yudisium \\
\hline $\begin{array}{c}\text { Mampu menyusun jadwal } \\
\text { ujian wawancara calon } \\
\text { mahasiswa }\end{array}$ & Ms.Excel & Jadwal availabilitas dosen \\
\hline $\begin{array}{c}\text { Mampu mengolah data } \\
\text { akademik }\end{array}$ & $\begin{array}{l}\text { Ms.Word, } \\
\text { Ms.Excel }\end{array}$ & Data akademik \\
\hline $\begin{array}{c}\text { Mampu memberikan } \\
\text { informasi akademik } \\
\text { kepada dosen maupun } \\
\text { mahasiswa }\end{array}$ & $\begin{array}{c}\text { Mailist } \\
\text { Departemen }\end{array}$ & Data akademik \\
\hline
\end{tabular}

\section{E. Penentuan Indikator Penilaian}

Indikator penilaian dilakukan dengan menentukan level kompetensi berdasarkan kompetensi yang telah diidentifikasi sebelumnya yakni kompetensi inti, kompetensi pendukung dan kompetensi teknis. Kompetensi inti dan kompetensi pendukung ditentukan berdasarkan kamus kompetensi Spencer \& Spencer, University of Guelph dan Harvard [4][5] dan [6] serta berdasarkan Taksonomi Bloom yaitu enam level kompetensi Kompetensi teknis ditentukan berdasarkan Taxonomi Bloom. Berikut ini merupakan contoh hasil penentuan indikator kompetensi inti.

Tabel 5.

Contoh Indikator Kompetensi Inti Achivement Orientation

\begin{tabular}{ll}
\hline \hline $\begin{array}{l}\text { Kode } \\
\text { Kompetensi }\end{array}$ & ACH \\
\hline $\begin{array}{c}\text { Kompetensi } \\
\text { Definisi }\end{array}$ & $\begin{array}{l}\text { Achievement Orientation / Semangat Berprestasi } \\
\text { Derajat kepedulian seseorang terhadap pekerjaannya }\end{array}$
\end{tabular}


sehingga terdorong berusaha untuk bekerja dengan lebih baik atau diatas standard.

\begin{tabular}{|c|c|}
\hline Level & Indikator Perilaku \\
\hline 1 & $\begin{array}{l}\text { Mengetahui tugas yang diberikan dan berfokus untuk } \\
\text { menyelesaikan tugas dengan baik. }\end{array}$ \\
\hline 2 & $\begin{array}{l}\text { Bermotivasi untuk mengerjakan tugas dengan baik dan } \\
\text { berusaha untuk mengerjakan sesuai standar rata - rata } \\
\text { yang ditetapkan. }\end{array}$ \\
\hline 3 & $\begin{array}{l}\text { Berusaha untuk mengerjakan tugas dengan baik } \\
\text { melebihi standar rata - rata yang ditetapkan. }\end{array}$ \\
\hline 4 & $\begin{array}{l}\text { Mampu menetapkan ukuran prestasi kerja sendiri tanpa } \\
\text { pedoman performansi dari atasan. }\end{array}$ \\
\hline 5 & $\begin{array}{l}\text { Mengkritisi performasi sebelumnya dan terus berusaha } \\
\text { memperbaiki performansi. }\end{array}$ \\
\hline 6 & $\begin{array}{l}\text { Menetapkan target yang menantang dan berusaha } \\
\text { untuk membuat perencanaan pencapaian target } \\
\text { kedepan. }\end{array}$ \\
\hline
\end{tabular}

Pada penentuan indikator perilaku diatas berdasarkan pada kamus kompetensi Spencer \& Spencer. Pada kamus tersebut terdapat level kompetensi mulai dari -1 hingga 8 . Untuk mereduksi menjadi 6 level berdasarkan Taxonomy Bloom dilakukan pencocokan dengan kata kunci pada Taxonomy Bloom. Berikut ini merupakan contoh hasil identifikasi indikator kompetensi pendukung.

Tabel 6.

Contoh Indikator Kompetensi Pendukung Planning and Organizing

\begin{tabular}{|c|c|}
\hline $\begin{array}{l}\text { Kode } \\
\text { Kompetensi }\end{array}$ & $\mathrm{PO}$ \\
\hline & Planning and Organizing/ Perencanaan dan \\
\hline Kompetensi & Pengorganisasian \\
\hline Definisi & $\begin{array}{l}\text { Mendefinisikan tugas untuk mencapai tujuan sekaligus } \\
\text { memastikan penggunaan sumber daya secara optimal } \\
\text { untuk mencapai tujuan. }\end{array}$ \\
\hline Level & Indikator Perilaku \\
\hline 1 & $\begin{array}{l}\text { Merencanakan tugas dan mengatur pekerjaan secara } \\
\text { mandiri. }\end{array}$ \\
\hline 2 & $\begin{array}{l}\text { Mengidentifikasi kebutuhan dan penggunaan sumber daya } \\
\text { yang optimal. }\end{array}$ \\
\hline 3 & Menerapkan perencanaan agar tujuan dapat tercapai. \\
\hline 4 & Mengembangkan rencana untuk unit bisnis \\
\hline 5 & $\begin{array}{l}\text { Mengintegrasikan dan mengevaluasi rencana untuk dapat } \\
\text { mencapai tujuan. }\end{array}$ \\
\hline 6 & $\begin{array}{l}\text { Mengembangkan rencana strategis dengan } \\
\text { mempertimbangkan persyaratan jangka pendek serta } \\
\text { jangka panjang. }\end{array}$ \\
\hline
\end{tabular}

Penentuan indikator penilaian untuk kompetensi teknis didasarkan pada level pada Taxonomy Bloom. Penentuan level berdasarkan pada kata kunci "mengetahui", "memahami", "mengaplikasikan", "menganalisis", "mengevaluasi" dan "membuat" [7]. Berikut ini merupakan contoh indikator penilaian untuk kompetensi teknis.

Tabel 7.

Contoh Indikator Kompetensi Teknis Pengadministrasi Akademik Program Pascasarjana

\begin{tabular}{lllllll}
\hline \hline $\mathrm{N}$ & \multicolumn{7}{c}{ Indikator } \\
\cline { 2 - 7 } & 1 & 2 & 3 & 4 & 5 & 6 \\
\hline
\end{tabular}

\begin{tabular}{|c|c|c|c|c|c|}
\hline \multirow{9}{*}{$\begin{array}{c}\text { Mengeta } \\
\text {-hui cara } \\
\text { menyu- } \\
\text { sun } \\
\text { jadwal } \\
\text { perkuliah } \\
\text { an dan } \\
\text { perwali- } \\
\text { an }\end{array}$} & \multirow{9}{*}{$\begin{array}{l}\text { Memaha } \\
\text { mi cara } \\
\text { menyu- } \\
\text { sun } \\
\text { jadwal } \\
\text { perkulia } \\
\text { han dan } \\
\text { perwali- } \\
\text { an }\end{array}$} & \multirow{9}{*}{$\begin{array}{c}\text { Meng- } \\
\text { klasifik } \\
\text { asikan } \\
\text { jadwal } \\
\text { perkuli } \\
\text { ahan } \\
\text { dan } \\
\text { perwali } \\
\text { an }\end{array}$} & \multirow{3}{*}{$\begin{array}{l}\text { Mengana } \\
\text { lisis } \\
\text { penyusu }\end{array}$} & \multirow{2}{*}{\multicolumn{2}{|c|}{ Mengeva }} \\
\hline & & & & & \\
\hline & & & & luasi & Menyu \\
\hline & & & penyusu & penyusu & sun \\
\hline & & & nan & nan & jadwal \\
\hline & & & jadwal & jadwal & perkulia \\
\hline & & & perkulia & perkulia & han dan \\
\hline & & & han dan & h-an dan & perwalia \\
\hline & & & $\begin{array}{c}\text { perwalia } \\
n\end{array}$ & $\begin{array}{c}\text { perwalia } \\
n\end{array}$ & $\mathrm{n}$ \\
\hline Mengeta & Memaha & Melak- & $\begin{array}{c}\text { Mengana } \\
\text { lisis }\end{array}$ & $\begin{array}{c}\text { Mengeva } \\
\text { luasi }\end{array}$ & $\begin{array}{l}\text { Mengem } \\
\text {-bangkan }\end{array}$ \\
\hline -hui cara & mi cara & sanaka & proses & proses & proses \\
\hline input & imput & II IITu & input & input & input \\
\hline data pada & nads & nada & data & data & data \\
\hline SIM & pada & pada & pada & pada & pada \\
\hline Akade- & SIM & SIM & SIM & SIM & SIM \\
\hline mik & $\begin{array}{l}\text { Aкade- } \\
\text { mik }\end{array}$ & $\begin{array}{l}\text { Aкade } \\
\text { mik }\end{array}$ & $\begin{array}{c}\text { Akade- } \\
\text { mik }\end{array}$ & $\begin{array}{l}\text { Akade- } \\
\text { mik }\end{array}$ & $\begin{array}{c}\text { Akade- } \\
\text { mik }\end{array}$ \\
\hline Mengeta & Memaha & $\begin{array}{l}\text { Meng- } \\
\text { konsep }\end{array}$ & Mengana & Mengeva & \\
\hline -hui cara & mi cara & -kan & lisis cara & luasi cara & Menyiap \\
\hline $\begin{array}{l}\text { menyiap } \\
\text {-kan }\end{array}$ & -kan & persiap & -kan & penyiapa & -kan \\
\hline form & form & an & form & $\mathrm{n}$ form & $f o$ \\
\hline kendali & kendali & kendali & kendali & perkulia & $\begin{array}{l}\text { Kendal1 } \\
\text { perkulia }\end{array}$ \\
\hline $\begin{array}{l}\text { perkuliah } \\
\text { an }\end{array}$ & $\begin{array}{c}\text { perkulia } \\
\text { han }\end{array}$ & $\begin{array}{c}\text { perkuli } \\
\text { ahan }\end{array}$ & $\begin{array}{c}\text { perkulia } \\
\text { h-an }\end{array}$ & h-an & han \\
\hline
\end{tabular}

\section{F. Perancangan Model Pengukuran}

Perancangan model scorecard pengukuran Human Capital Readiness dilakukan berdasarkan dimensi - dimensi yang telah ditentukan sebelumnya yaitu kompetensi inti, kompetensi pendukung dan kompetensi teknis serta tools dan resource. Perancangan model scorecrecard ini dilakukan setelah dilakukan validasi isi kepada expert dan penentuan target setiap kompetensi oleh expert. Berikut ini merupakan hasil perancangan mekanis me pengukuran HCR.

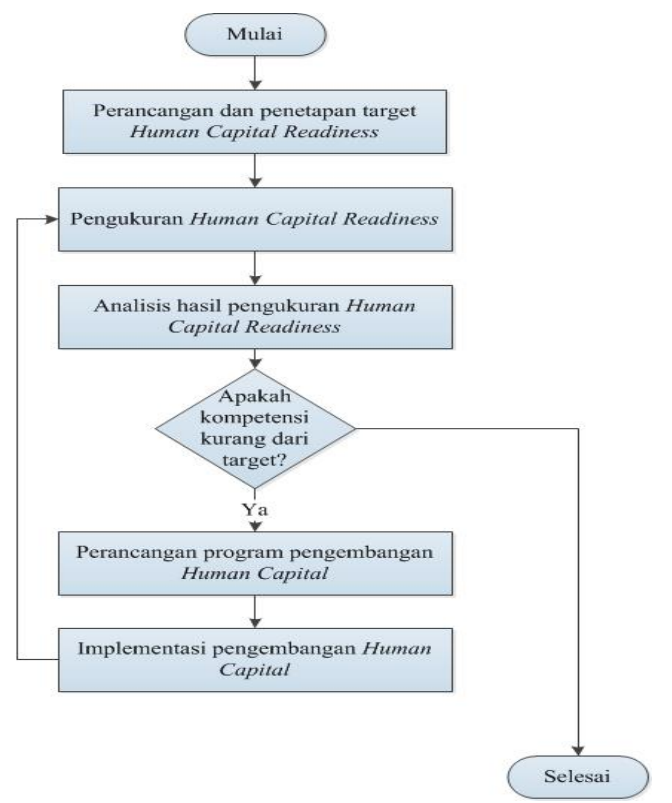

Gambar 2. Mekanisme Pengukuran Human Capaital Readiness

Scorecard pengukuran Human Capital Readiness dirancang berdasarkan kebutuhan kompetensi pada setiap 
jabatan yang terdiri dari kompetensi innti, kompetensi pendukung, kompetensi teknis, tools dan resource dan target yang telah ditentukan. Pengisian pengukuran dilakukan dengan memberikan centang pada setiap kompetensi dimulai dari kompetensi inti, kemudian kompetensi pendukung, lalu dilanjutkan dengan kompetensi teknis serta tools dan resource. Berikut ini merupakan contoh scorecard pengukuran untuk kompetensi inti.

Tabel 8.

Contoh Scorecard Pengukuran Petugas Perpustakan.

Nama :

Jabatan :

Unit Kerja:

\section{Kompetensi Inti}

\begin{tabular}{|c|l|c|c|c|c|c|c|c|}
\hline \multirow{2}{*}{$\begin{array}{c}\mathrm{N} \\
\mathrm{o}\end{array}$} & \multicolumn{1}{|c|}{ Kompetensi } & \multicolumn{5}{|c|}{ Level } & $\begin{array}{c}\text { Tar } \\
\text { get }\end{array}$ \\
\cline { 2 - 8 } & 1 & 2 & 3 & 4 & 5 & 6 & $\begin{array}{l}\text { Achievement } \\
\text { Orientation }\end{array}$ \\
\hline 2 & $\begin{array}{l}\text { Impact and } \\
\text { Influence }\end{array}$ & & & & & & & 3 \\
\hline 3 & $\begin{array}{l}\text { Organizational } \\
\text { Commitment }\end{array}$ & & & & & & & 3 \\
\hline 4 & $\begin{array}{l}\text { Relationship } \\
\text { Building }\end{array}$ & & & & & & & 2 \\
\hline 5 & $\begin{array}{l}\text { Continuous } \\
\text { Learning }\end{array}$ & & & & & & & 3 \\
\hline 6 & Creative Thinking & & & & & & & 3 \\
\hline 7 & Team Leadership & & & & & & & 2 \\
\hline
\end{tabular}

Kompetensi Pendukung

\begin{tabular}{|c|c|c|c|c|c|c|c|c|}
\hline \multirow{2}{*}{ No } & \multirow{2}{*}{ Kompetensi } & \multicolumn{6}{|c|}{ Level } & \multirow{2}{*}{ Target } \\
\hline & & 1 & 2 & 3 & 4 & 5 & 6 & \\
\hline 1 & Planning and Organizing & & & & & & & 2 \\
\hline 2 & Risk Management & & & & & & & 3 \\
\hline 3 & Communication & & & & & & & 3 \\
\hline 4 & Concern for Order & & & & & & & 3 \\
\hline 5 & Initiative & & & & & & & 2 \\
\hline 6 & Managing Work & & & & & & & 3 \\
\hline 7 & Technical/Professional Skill & & & & & & & 2 \\
\hline 8 & Follow Up & & & & & & & 2 \\
\hline 9 & Teamwork and Cooperation & & & & & & & 1 \\
\hline 10 & Customer Service Orientation & & & & & & & 2 \\
\hline 11 & Flexibility & & & & & & & 1 \\
\hline 12 & Meeting Partisipation & & & & & & & 2 \\
\hline
\end{tabular}

Pengukuran Human Capital Readiness berdasarkan scorecard pengukuran yang telah dirancang. Pengukuran Human Capital Readiness dilakukan oleh atasan langsung dan atasan dari atasan langsung. Pada pengukuran Human Capital Readiness di Departemen, pengukuran dilakukan oleh Kasubbag Tata Usaha dan Kepala Departemen.

\section{KESIMPULAN}

Jabatan yang terlibat langsung dalam core process Depertemen yaitu jabatan Pengadministrasi Akademik program Pascasarjana, Pengadministrasi Akademik program Sarjana, Pengadministrasi Kemahasiswaan dan alumni, Petugas Perpustkaan dan Teknisi Sarana Prasarana. Terdapat 7 kompetensi inti untuk seluruh tenaga kependidikan, 13 Kompetensi Pendukung untuk Jabatan Pengadministrasian Akademik Program Pascasarjana, 13 Kompetensi Pendukung untuk Jabatan Pengadministrasian Akademik Program Sarjana, 11 Kompetensi Pendukung untuk Jabatan Pengadministrasi Kemahasiswaan dan alumni, 12 Petugas Perpustakaan dan Teknisi Sarana Prasarana. Sedangkan untuk kompetensi teknis dapat diidentifikasi 16 Kompetensi teknis untuk Jabatan Pengadministrasian Akademik Program Pascasarjana, 16 Kompetensi teknis untuk Jabatan Pengadministrasian Akademik Program Sarjana, dan 8 Kompetensi Teknis untuk Jabatan Pengadministrasi Kemahas is waan dan alumni, Petugas Perpustakaan dan Teknisi Sarana Prasarana.Model Scorecard Human Capital Readiness terdiri dari dimensi-dimensi yang akan diukur pada Human Capital Readiness antara lain kompetensi inti, kompetensi pendukung, kompetensi teknis serta tools dan resource.

\section{DAFTAR PUSTAKA}

[1] R. S. Kaplan and D. Norton, Strategy Maps. Massachusets: Harvard Business School Press Boston, 2004.

[2] P. Ngin, "Applying Human Capital Management to Model Manpower Readiness: A Conceptual Frameworl," California, 2005.

[3] S. Kurniawati, "Human Capital di Perguruan Tinggi," Bandung, 2014.

[4] L. Spencer and S. Signe, Competence at Work, Models for Superior Performance. Canada: John Wiley \& Sons, 1993.

[5] U. Guelph, Behavioral Competency Dictionary. Ontario: University of Guelph, 2010.

[6] Harvard University, "Competency Dictionary," Cambridge, 2007.

[7] L. . Anderson and D. Krathwol, A Taxonomy for Learning, Teaching and Assesing: A Revision of Bloom's Taxonomy of Educational Objectives. A Bridged Edition. New York: Addison Wesley Longman,Inc, 2001. 